\title{
A Comprehensive Software Project Management Framework
}

\author{
Mohamed Ellithey Barghoth'1, Akram Salah², Manal A. Ismail ${ }^{3}$ \\ ${ }^{1}$ Egyptian E-Learning University (EELU), Giza, Egypt \\ ${ }^{2}$ Computer and Information Sciences, Cairo University, Giza, Egypt \\ ${ }^{3}$ Computer Engineering and System Department, Engineering, Helwan University, Helwan, Egypt \\ Email: mohamed.ellithey@yahoo.com, akramsalah.21@gmail.com, and manal_shoman@yahoo.com
}

How to cite this paper: Barghoth, M.E., Salah, A. and Ismail, M.A. (2020) A Comprehensive Software Project Management Framework. Journal of Computer and Communications, 8, 86-102.

https://doi.org/10.4236/jcc.2020.83009

Received: February 3, 2020

Accepted: March 14, 2020

Published: March 17, 2020

Copyright $\odot 2020$ by author(s) and Scientific Research Publishing Inc. This work is licensed under the Creative Commons Attribution International License (CC BY 4.0).

http://creativecommons.org/licenses/by/4.0/

\begin{abstract}
Project management is vital for software project success. Project Management Body of Knowledge (PMBOK), CMMI for Development (CMMI-DEV), and other software project management models and practices established to assist software organizations, each of these models offers diverse focal points. Combined effective software project management practices remain a challenge to software organizations. In striving to raise the likelihood of software project success, this paper introduces a framework for software project management effectiveness which integrated a set of software project management practices based on the PMBOK guide processes, CMMI-DEV processes, and management areas that influence a software project. The proposed framework called 4PTRB which includes people, process, product, project, technology, risk, and business management areas. The 4 PTRB software project management framework provides a whole comprehensive view to help software project managers to improve their project management effectiveness. The framework is validated by conducting a web-based survey of software professional practitioners around the world. A statistical analysis of twenty software projects has been conducted as a case study thereafter, spanning small to large development projects. The consistency of the case study and survey results shows the power of the 4 PTRB framework as an inclusive software project management framework.
\end{abstract}

\section{Keywords}

CMMI, PMBOK, Software Project Management Effectiveness, Software Project Management Framework

\section{Introduction}

In recent times, the software industry has been regarded as one of the world's 
largest economies [1]. At the same time, projects are an important route to generate business value and benefits for organizations. A typical software project manager must be prepared to handle various contract kinds and procurement methods. In addition, he/she has to accomplish the software project with tighter budgets, shorter timelines, resource deficiency, and rapidly vibrant technology. With an accelerating rate of change, the market environment is dynamic. Thus, companies handle software projects to systematically produce business value in order to stay viable within the world economy [2].

Project management practices are considered one of the software project success factors [3]-[7]. In today's rapidly evolving business climate, software projects require the application of software engineering concepts besides project management effectiveness abilities to deliver a successful project outcome [8]. For the achievement of any business, project management is essential, regardless of software project size [9]. It doesn't just ensure the project's success but enable managers to jointly identify various elements of a business that seem to be essential to software organizations [10]. Regardless of the evolution phase of your business, imposing effective project management is essential to elevate your business to the following level. The goal of this study is to develop a comprehensive software project management framework according to an extensive literature review of software project management frameworks and models to promote software project success probability.

The structure of the paper is as follows. A brief background of related frameworks and models is discussed in section 2. Section 3 introduces the proposed comprehensive framework. As well as the qualitative and quantitative research validity methods used are explained in section 4 . Section 5 demonstrates the research discussion. Finally, the conclusion that has been drawn from this research along with the suggestion of future work is shown in section 6 .

\section{Background}

Without a doubt, software projects are greatly challenging and numerous research has risen that focus on the improvement of software development processes, methodologies, frameworks and the technology utilized amid managing software projects [11]-[18]. In any case, software project management is pivotal for each software development effort. Nevertheless, a comprehensive software project management framework to plan and execute a project certainly makes a difference.

PMBOK guide and CMMI-DEV are two of the most widely recognized works [19]. They have a process-oriented view on project management [20]. Projects are managed as a set of processes. Product, Project, and People (3P's) list primary competencies which are utilized by the most successful software project managers [21]. The (3P's) model has a competency-based approach for software project management. People, Product, Process, and Project (4P's) [22], as well as People, Process, Product, and Risk (3PR) frameworks, are concentrates on effec- 
tive software project management practices [23] [24] [25]. The main management areas stated in the existing software project management models and frameworks illustrated in Table 1.

While the Project Management Institute (PMI) points out the significance of human resource management [26]. Also, the skilled people considered as one of three Software Engineering Institute (SEI) critical dimensions [27], they do not go into the details of people management in the project environment to develop high-quality software products [28]. However, the PMBOK guide affirmed the importance of technical project management, and CMMI-DEV declared the value of tools and equipment will be used during the project, the technology area doesn't include in-depth. In addition to the (3P's) model are not detailed the processes that are necessary to deliver the software projects. As well as, the (4P's) and (3PR) frameworks covered many management areas, deeply business angle and technological aspects are somewhat overlooked and not mentioned.

The choosing of a software project management framework can be one of the challenging duties and can have an impact on the future of the project [11]. Usually, the project manager criteria for chose the management framework of the software project is mainly based on subject-matter expert preferences, similar previous experience, organization rules, or even stakeholders' opinion.

As each software project management framework or model provide differ advantage and point of view distinct than others [12] [17] [29]. When the project manager selects to execute a specific framework, he/she may need some additional areas, practices or even skills outside the framework followed.

Accordingly, with the purpose of less dependency on a single project management framework, besides adding the business and technology perceptions to offer a whole view. This research introduces a comprehensive software project management framework by integrating the previous project management models and frameworks to help project managers to deliver a successful software project. The proposed software project management framework will be discussed in detail next section.

Table 1. Main management areas and their correspondence to the existing models and frameworks.

\begin{tabular}{cccc}
\hline \multirow{2}{*}{ Main Management Area } & \multicolumn{3}{c}{ Software Project Management Models and Frameworks } \\
\cline { 2 - 4 } & 3P's & 4P's & 3PR \\
\hline People & $\checkmark$ & $\checkmark$ & $\checkmark$ \\
Process & & $\checkmark$ & $\checkmark$ \\
Product & $\checkmark$ & $\checkmark$ & \\
Project & $\checkmark$ & & $\checkmark$ \\
Technology & & & \\
Risk & & & \\
Business & & & \\
\hline
\end{tabular}




\section{Proposed Framework}

Proposed software project management framework derived from those previous models, which integrated a set of software project management practices based on the PMBOK guide processes, CMMI for Development (CMMI-DEV) processes, and management areas which influence on a software project to serve as guiding principles for the software project management discipline.

Moreover, two software management areas added to the existing models and frameworks to provide a comprehensive vision. One of these main areas is related to the business perspectives and aspects of managing the financial operations to deliver a software product in the direction of obtaining a commercial value in today's competitive market.

While another main software management area included in the proposed framework concerns the technology side. The software project manager has to mind out of technological knowledge and different technical angles to produce a highly performed software product.

The proposed framework consists of seven main software management areas: People, Process, Product, Project, Technology, Risk, and Business (4PTRB). These main software management areas contain twenty-eight sub-areas over the project lifecycle shown in Figure 1. The five main areas and its related sub-areas

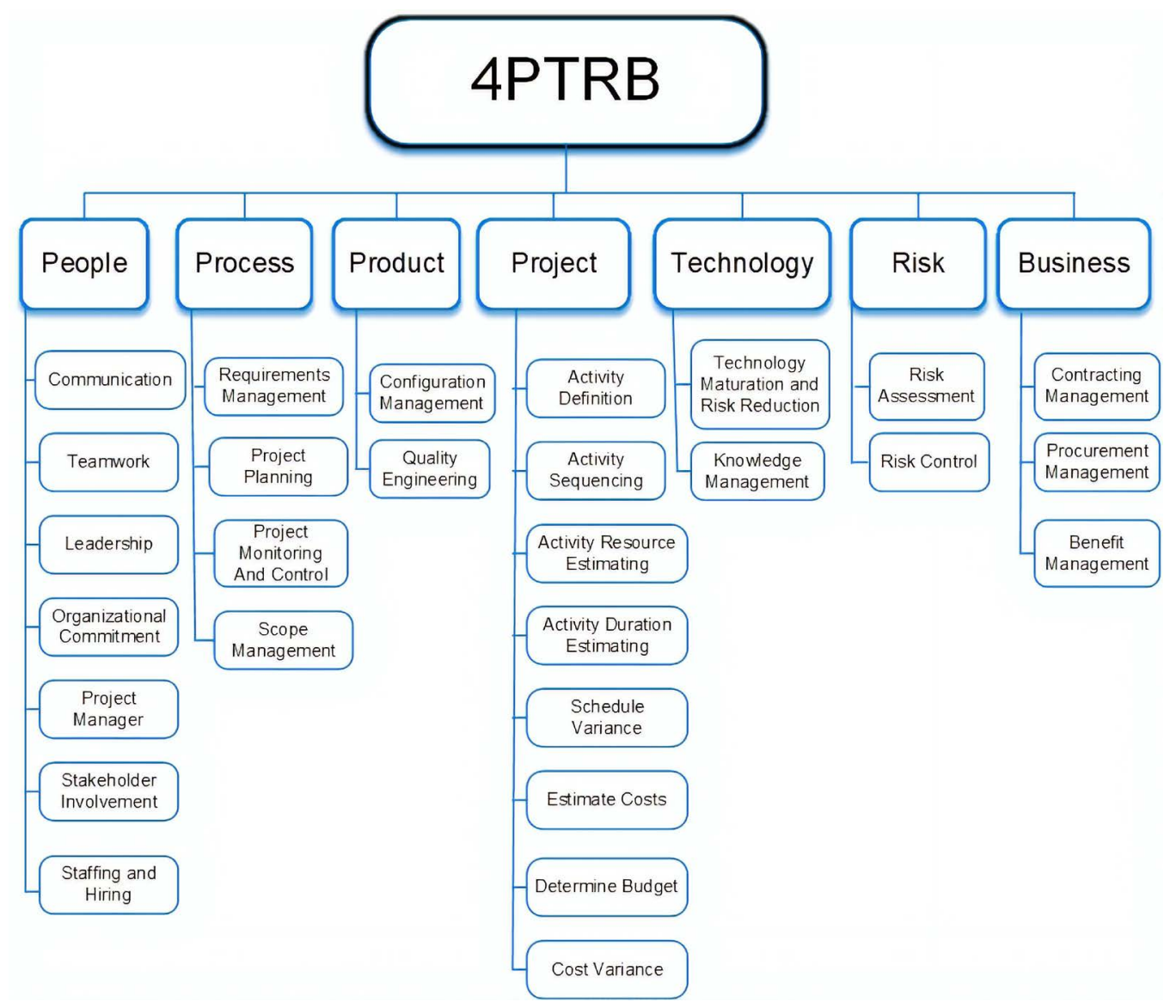

Figure 1. The proposed software project management framework (4PTRB). 
that have been included in software management frameworks and models described previously are people, process, product, project, and risk. Therefore, we will not go to discuss them in detail. Technology and business are the main areas that have been added to make the framework inclusive. These two software management areas decomposed into five sub-areas, which briefly described in this section.

\subsection{Technology}

Technology management is a set of management disciplines that enables organizations to manage their technological backbone to form competitive business advantage, improve software products and services. Technology development is an iterative way regarding maturing technologies, boost knowledge, and refining user performance [30] [31].

\subsubsection{Technology Maturation and Risk Reduction}

The purpose of the Technology Maturation \& Risk Reduction (TMRR) sub-area is to consider the maturity and fitness of a particular technology involves determining its readiness for operations by project team to reduce technology risk, engineering integration, buying down technical issues and developing an appropriate understanding of a software solution in order to support business decisions and to define the acceptable set of technologies to be joined into a whole software system.

\subsubsection{Knowledge Management}

Knowledge management concern with making sure the skills, experience, and proficiency of the project stakeholders including the project team are well utilized at an earlier point of the software project. Manage project knowledge sub-area concentrate on using existing knowledge, creating new knowledge to achieve the project's objectives and contribute to organizational learning, sharing knowledge to empower project stakeholders, and obtaining lessons learned at the end of the project [32].

\subsection{Business}

The business management area contains aspects of supervision and administering business and financial operations. Software business management concern with the commercial actions of the software industry, aimed at producing, buying and selling software products or services.

\subsubsection{Contracting Management}

Contract management or contract administration is a concern about managing the contract creation, negotiation, execution, alteration and termination of contracts with various parties including customers, vendors, distributors, sub-contractors, and employees [33] [34]. The contract management sub-area goal is to maximize operational and financial performance at an organization, with the intention of reducing financial risk. 


\subsubsection{Procurement Management}

Project procurement management includes the processes necessary in conformity with the purchase or acquires products, services, or materials desired from outside the project crew. The software project manager would also specify the procurement approach, procurement relationships, and identify potential sellers.

\subsubsection{Benefit Management}

Benefit management focuses on recognizing, preparing, tracking, and realizing business benefits [35]. PMI terms business value as much the net quantifiable benefit derived out of a business endeavor. The goal of benefits management sub-area is to increase the business values of software project implementation, maximize the financial impact on the organization, and sustaining the benefits provided by a project.

In this research, software project management effectiveness has been measured based on the software management areas included in the 4PTRB framework. Therefore, the Project Management Effectiveness (PME) formula consists of the summation of each main software management area score. These main areas are not equally weighted. A web-based survey has been carried out to provide a rating of each main software management area. The framework validation methods including the survey and case study will be presented in the next section.

$$
\begin{aligned}
\text { PME Score }= & \text { PeopleS }+ \text { Process } S+\text { ProductS }+ \text { ProjectS } \\
& + \text { TechnologyS }+ \text { RiskS }+ \text { BusinessS }
\end{aligned}
$$

where:

PME Score: Software Project Management Effectiveness Score;

PeopleS: People Main Area Score;

ProcessS: Process Main Area Score;

ProductS: Product Main Area Score;

ProjectS: Project Main Area Score;

TechnologyS: Technology Main Area Score;

RiskS: Risk Main Area Score, and;

BusinessS: Business Main Area Score.

\section{Framework Validation}

After the development of the 4PTRB framework, it has been validated by a survey with the participation of software professional practitioners around the globe as a first stage on the way to validate the framework. Variation of participants' roles, experience, organization type, and software application kind they have participated in the survey, strengthens the framework. Posteriorly, it is followed by a case study stage on twenty software projects as a dataset with a diverse scope, budget, and period. A statistical analysis of software professional practitioners' reply and case study dataset results revealed that the framework is valid. Those results will be presented in this section. The research process is represented in Figure 2. 


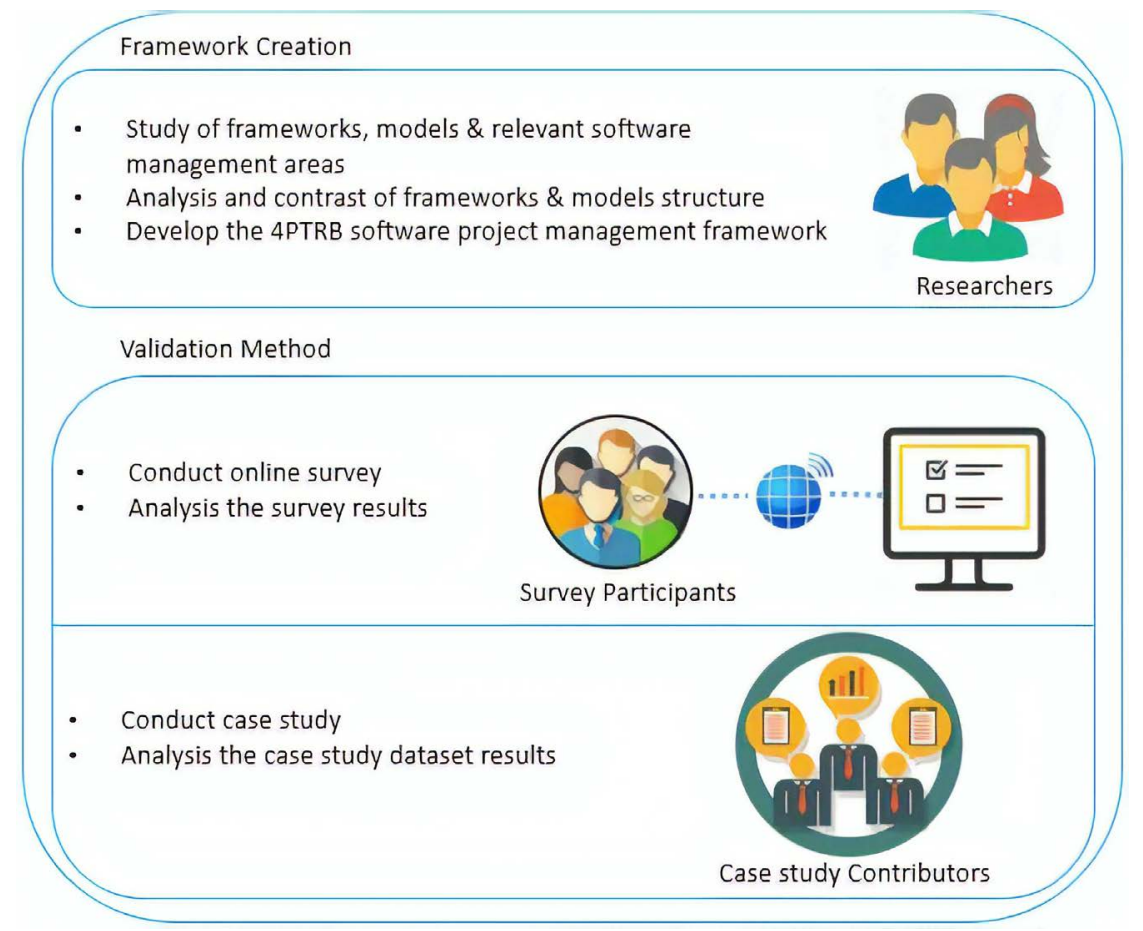

Figure 2, Research process.

\subsection{Survey}

In order to validate the framework developed earlier to be widely applied. A web-based survey study was devised among software professional practitioners worldwide. The survey was anonymous, but respondents had the opportunity to leave their contact information if they were eager to discuss the results of the survey with the author. There were one hundred twenty-six responses to the survey, three of them expressed their scarcity of experience in the field, so their results were left out. Accordingly, the total number was one hundred twenty-three valid responses and the average time to complete was around five minutes.

The web-based survey contained nineteen questions. Seventeen of them were mandatory which collect information regarding respondents and their previous experience as well as their opinion regarding the framework. While there were two optional questions where participants can mention management area, activity, concept, dimension or anything he/she would like to add in the framework and last question was about how much likely they are recommending this survey to a friend or colleague.

\section{Survey Results}

The web-based survey questions can be logically divided into three chunks, a chunk of questions that concerning the importance of management areas, another chunk was about the significance of the 4PTRB framework, while the third one to collecting information regarding respondents and their background experience. 
This survey helped to rank the importance of the main seven software management areas based on the analysis of respondents' choices as follows: People, Process, Product, Project, Technology, Risk, and Business. The first letters of these main areas are used in naming the framework. Therefore, it is named (4PTRB) framework. Rating of the main software management areas illustrated in Table 2 and Figure 3.

In this context, this rating helps to formulate the Project Management Effectiveness (PME) formula. PME formula derived from the Demir and Cullen studies [23] [25]. It consists of main area scores multiplied by their corresponding rating. The main area score formula consists of the summation of its associated sub-areas score divided by their count. While each sub software management area score is calculated via questioning software project manager a bundle of closed-form questions. These questions are placed into the PME questionnaire that assesses to which extent the software management area, its associated sub-area, and practices being applied.

PME Score $=$ PeopleS $\times 0.227+$ Process $S \times 0.196+$ ProductS $\times 0.172+$ ProjectS $\times 0.153$ + TechnologyS $\times 0.141+$ RiskS $\times 0.074+$ Business $\times 0.037$

Table 2. Ranking of main software management areas.

\begin{tabular}{ccc}
\hline Rank & Management Areas & Rating (In Percentage) \\
\hline $\mathbf{1}$ & People & $22.7 \%$ \\
$\mathbf{2}$ & Process & $19.6 \%$ \\
$\mathbf{3}$ & Product & $17.2 \%$ \\
$\mathbf{4}$ & Project & $15.3 \%$ \\
$\mathbf{5}$ & Technology & $14.1 \%$ \\
$\mathbf{6}$ & Risk & $7.4 \%$ \\
7 & Business & $3.7 \%$ \\
\hline
\end{tabular}

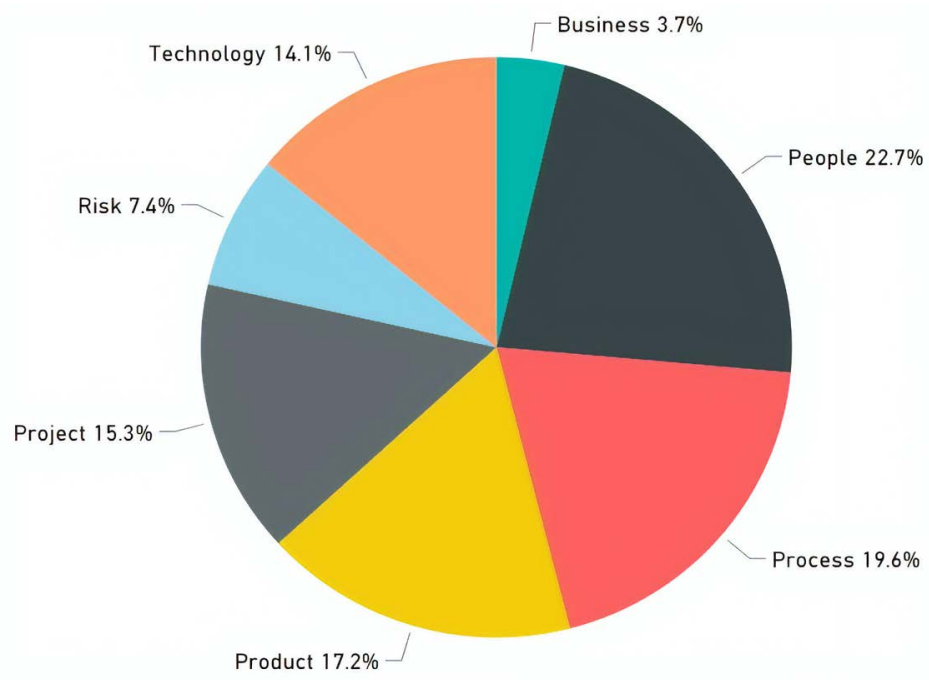

Figure 3. Rating of main software project management areas. 
Respondents were asked to what extent they think 4PTRB framework significant to serve as guiding principles for the software project management discipline, results represent that the framework is valuable as shown in Table 3.

The survey was populated, and respondents global wide were asked to recall the last projects they participated in or projects that they have thorough knowledge about. In this paper, descriptive and analytical statistics used to interpret the results. Distribution of the respondents around the world is shown in Figure 4.

Software professional practitioners were participated in different roles in software projects, whereas 57 of respondents were project manager constitute the majority. The respondents' roles are illustrated in Figure 5.

Table 3. The significance of the 4PTRB framework.

\begin{tabular}{|c|c|c|c|c|c|c|c|}
\hline Results & $\begin{array}{c}\text { Very } \\
\text { Important }\end{array}$ & Important & $\begin{array}{l}\text { Somewhat } \\
\text { Important }\end{array}$ & Neutral & Unimportant & $\begin{array}{c}\text { No } \\
\text { Opinion }\end{array}$ & Total \\
\hline $\begin{array}{l}\text { Number of } \\
\text { Respondents }\end{array}$ & 70 & 36 & 15 & 2 & 0 & 0 & 123 \\
\hline Percentage & $56.9 \%$ & $29.3 \%$ & $12.2 \%$ & $1.6 \%$ & $0 \%$ & $0 \%$ & $100 \%$ \\
\hline
\end{tabular}

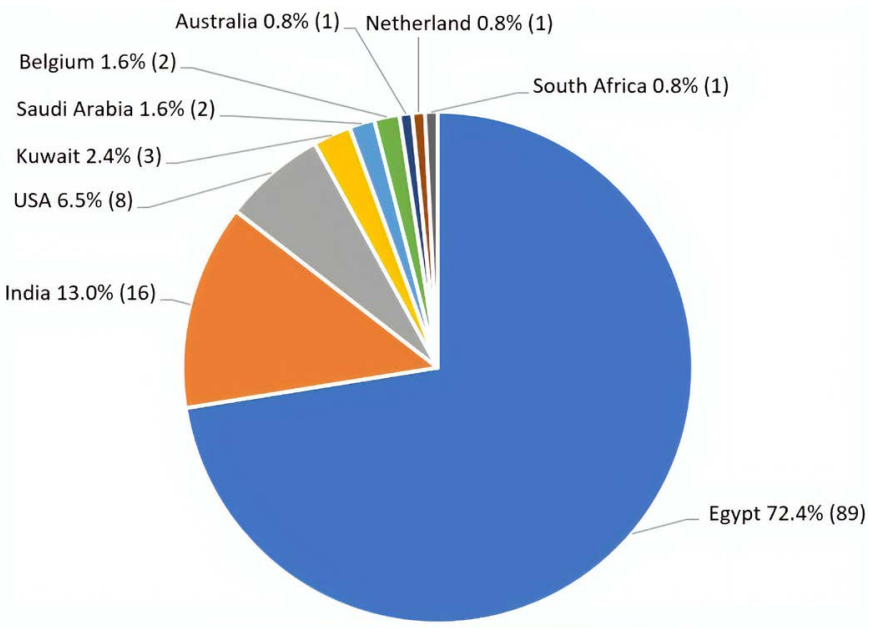

Figure 4. Distribution of the respondents around the world.

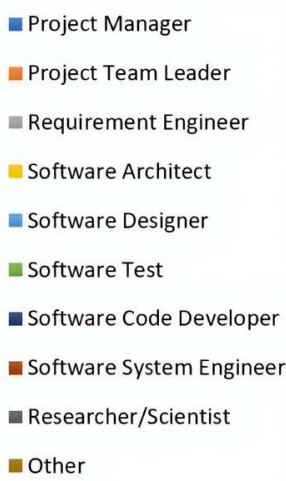

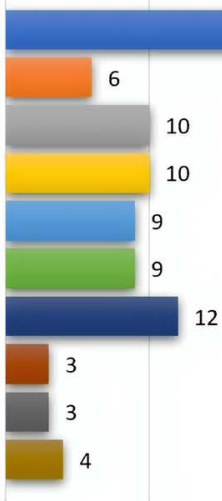

10

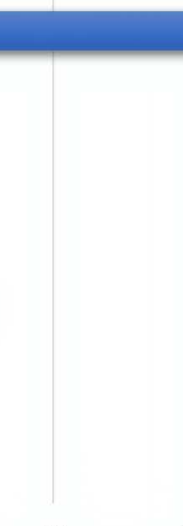

20

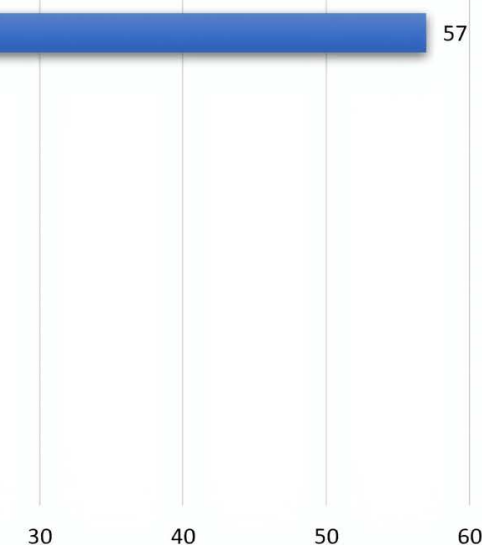

Figure 5. Respondents roles. 
Respondents had diverse years of experience, however, 27 of the respondents were revealed 9 years of experience as the most chosen choice. Figure 6 demonstrated a different year of experience of respondents.

Also, they have participated in a various number of software projects, results show that the majority of respondents participated in 10 projects, and twelve of respondents indicated that they participated in more than 10 projects. The survey results reflected the respondents' knowledge. The number of software projects that survey respondents had joined presented in Figure 7.

Besides, the survey tried to catch the type of organization in their projects during their previous experience as explained in Figure 8.

Moreover, respondents mentioned that they were involved in different kinds of software applications as shown in Figure 9.

The website holds the survey and the analysis of its results published and can be reviewed in detail by link [36]. In order to conduct a case study, a software project management effectiveness tool to quantitatively measure the project management effectiveness has been developed.

$\square 1$ Year
$\square 2$ Years
$\square 3$ Years
4 Years
$\square$ Years
$\square$ Years
$\square 7$ Years
$\square 8$ Years
$\square 9$ Years
$\square 10$ Years
$\square$ More than 10 Years

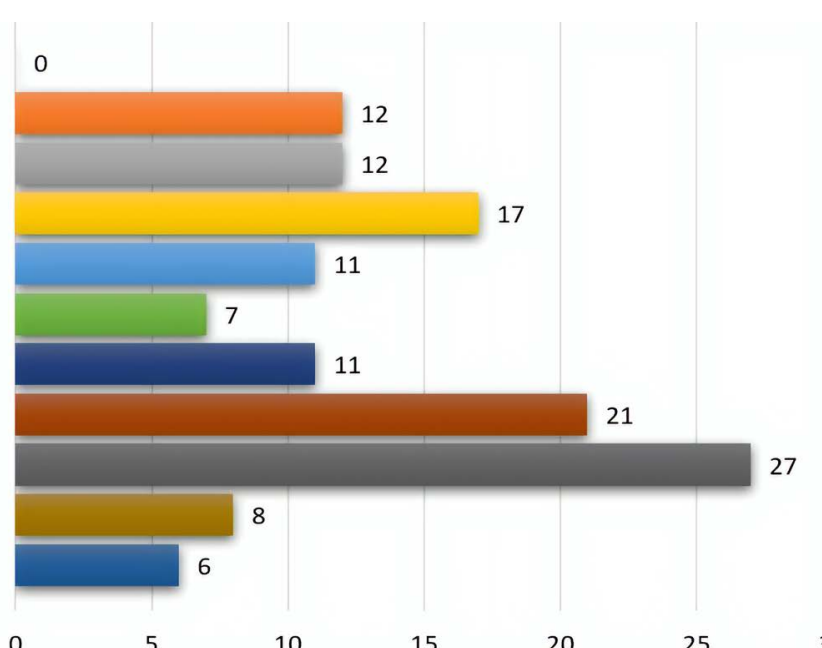

10
15

Figure 6. Respondents expertise.

$$
\begin{aligned}
& \square \text { Project } \\
& \square \text { Projects } \\
& \square 3 \text { Projects } \\
& \square 4 \text { Projects } \\
& \square 5 \text { Projects } \\
& \square 6 \text { Projects } \\
& \square 7 \text { Projects } \\
& \square 8 \text { Projects } \\
& \square 9 \text { Projects } \\
& \square 10 \text { Projects } \\
& \square \text { More than } 10 \text { Projects }
\end{aligned}
$$

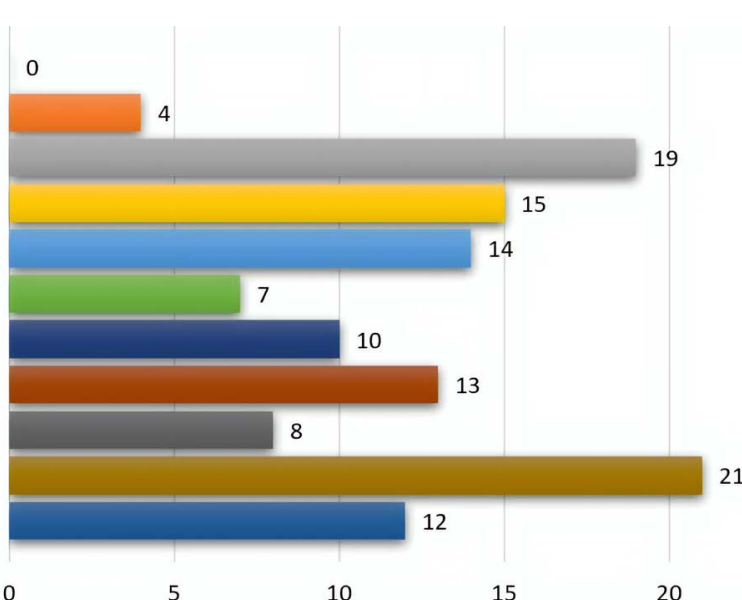

15

Figure 7. The number of software projects which survey respondents joined. 

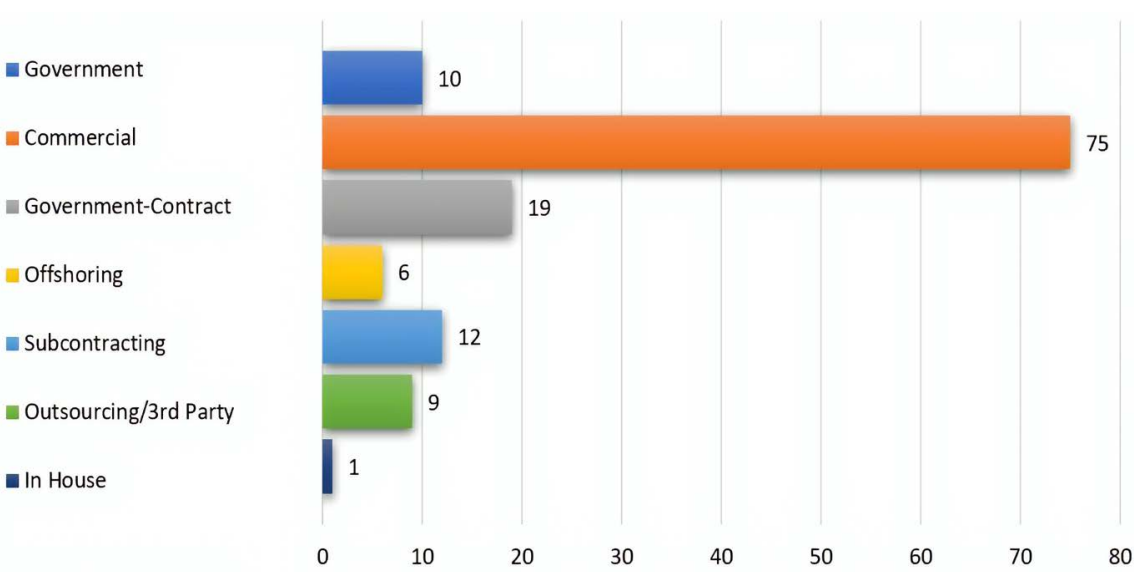

Figure 8. Organization types.

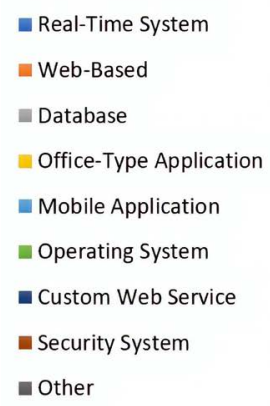

0

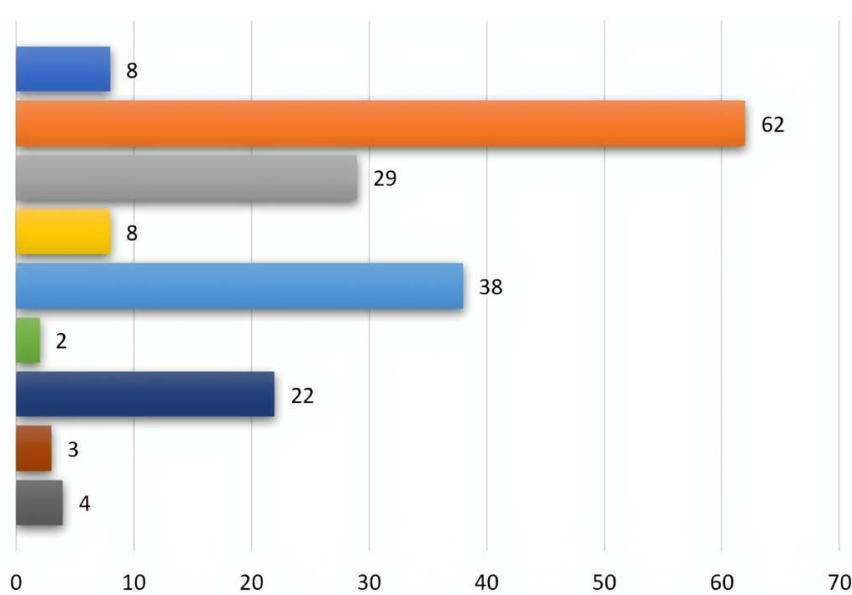

Figure 9. Kinds of software applications.

\subsection{Case Study}

The survey study is a vital part of the research. Likewise, the empirical support of the framework done by the case study is an important contribution of this research. We conducted a case study on an organization located in Egypt that concerns about building software products. The case study was on twenty software projects with different size, budget, and duration. These twenty software projects were within the timeframe of the 2018 year and led by eight project managers.

The study participants consisted of software project managers and executive managers. While the software project managers were partaking their project's data, the executive managers asked to grant project success score for every project based on scope, schedule, budget, customer satisfaction, and business value viewpoints. Software Project Management Effectiveness Evaluator (SPMEV) is an online tool developed to allow the case study participants to evaluate the software project management effectiveness of their software projects. It contains a self-administered PME questionnaire by asking the software project manager a set of closed-form questions during the project life cycle based on the imple- 
mentation of the 4PTRB framework management areas and practices.

\section{Case Study Results}

The study participants had privacy concerns, so the projects were named according to alphabetical order. Case study findings were interesting and consistent with survey results. Participants completed the PME questionnaire by themselves on their own time. Most of the study participants completed it within thirty minutes. Project success scores provided by participants and PME scores calculated by SPMEV were from zero to ten. Where a score of zero means a software project is not succeeded and the least effective project management has been applied by the software project manager. While a score ten means a successful software project and indicates that the most effective software project management has been applied.

To compare our results with previous studies, the 3PR framework and its associated project management effectiveness evaluation model have been implemented on the twenty software projects that included in the case study dataset and software project management effectiveness has been also measured.

The projects in the dataset are a good mix of projects in many aspects. As the rest of the projects show variability in size and cost. Almost all of the participants reported a high percentage of delivered functionality. The case study project schedules vary from four months to twelve months, whereas the average duration schedule of the projects in the dataset is eight months as shown in Table 4.

There was a strong positive correlation with the project success score and software project management effectiveness (PME) score as shown in Figure 10. The correlation between 4PTRB PME score and success score stronger than 3PR PME and success score. The Pearson correlation coefficient is 0.9505 , while it is 0.8276 when the $3 \mathrm{PR}$ framework applied. That means implementing the 4PTRB framework emphasizes the chance of delivering a successful software project.

In Demir's study [23], a lengthened PME questionnaire introduced as the average time to complete the questionnaire can be reached to three hours. In addition, the PME score has been measured by the author that took about four to six hours. As future work, an automated tool will significantly reduce the time to complete the process. Accordingly, we developed SPMEV as a web-based tool using the client-server model.

In this study, all optional and essay questions are neglected. So, the number of questions has been decreased. Also, the PME questionnaire divided by the project phase into five portions. That allows software project managers to submit the PME questionnaire in a shorter time, as case study participants completed the questionnaire in thirty minutes. SPMEV automatically measured the PME score promptly after submitting the PME questionnaire. Such findings reinforce the validity of the 4 PTRB framework. 
M. E. Barghoth et al.

Table 4. Case study dataset.

\begin{tabular}{|c|c|c|c|c|c|c|c|c|c|c|}
\hline Number & $\begin{array}{l}\text { Project } \\
\text { Name }\end{array}$ & $\begin{array}{c}\text { Planned } \\
\text { Cost/Actual } \\
\text { Cost (In } \\
\text { Thousand \$) }\end{array}$ & $\begin{array}{c}\text { Planned } \\
\text { Duration/Actual } \\
\text { Duration } \\
\text { (Months) }\end{array}$ & $\begin{array}{c}\text { Scope of } \\
\text { feature or } \\
\text { functions } \\
\text { delivered (\%) }\end{array}$ & $\begin{array}{l}\text { Project } \\
\text { Size in } \\
\text { term of } \\
(\text { KLOC) }\end{array}$ & $\begin{array}{l}\text { Average Number } \\
\text { of People } \\
\text { involved in the } \\
\text { project }\end{array}$ & $\begin{array}{l}\text { kind of software } \\
\text { applications }\end{array}$ & $\begin{array}{l}\text { Success } \\
\text { Rate }\end{array}$ & $\begin{array}{c}\text { PME } \\
\text { Score } \\
\text { (4PTRB) }\end{array}$ & $\begin{array}{l}\text { PME } \\
\text { Score } \\
\text { (3PR) }\end{array}$ \\
\hline 1 & A & $15 / 16.4$ & $6 / 7$ & $100 \%$ & 10 & 29 & Custom Web Service & 6 & 6.11 & 4.6 \\
\hline 2 & B & $25.6 / 27$ & $9 / 9$ & $100 \%$ & 10 & 36 & Web-Based & 6 & 6.4 & 7.68 \\
\hline 3 & $\mathrm{C}$ & $4 / 4$ & $4 / 4$ & $100 \%$ & 6 & 8 & Web-Based & 9 & 9.84 & 9.82 \\
\hline 4 & $\mathrm{D}$ & $6 / 6.8$ & $5 / 6$ & $100 \%$ & 8 & 15 & Custom Web Service & 7 & 6.43 & 5.91 \\
\hline 5 & $\mathrm{E}$ & $6 / 6.2$ & $8 / 8$ & $95 \%$ & 10 & 19 & Web-Based & 8 & 8.35 & 8.71 \\
\hline 6 & $\mathrm{~F}$ & $6 / 6.4$ & $9 / 11$ & $100 \%$ & 10 & 20 & Web-Based & 7 & 7.77 & 7.91 \\
\hline 7 & G & $7 / 7.9$ & $10 / 10$ & $84 \%$ & 16 & 21 & Mobile App & 6 & 6.02 & 5.46 \\
\hline 8 & $\mathrm{H}$ & $7 / 7.8$ & $11 / 10$ & $100 \%$ & 19 & 21 & Web-Based & 8 & 7.97 & 8.93 \\
\hline 9 & I & $38.5 / 39.5$ & $12 / 12$ & $90 \%$ & 23 & 43 & Database & 7 & 6.57 & 5.6 \\
\hline 10 & $\mathrm{~J}$ & $38 / 39$ & $11 / 11$ & $100 \%$ & 20 & 43 & Database & 6 & 5.79 & 5.32 \\
\hline 11 & K & $17.5 / 18.1$ & $9 / 11$ & $92 \%$ & 21 & 19 & Mobile App & 7 & 7.16 & 7.38 \\
\hline 12 & $\mathrm{~L}$ & $8 / 8.5$ & $8 / 8$ & $100 \%$ & 10 & 15 & Mobile App & 7 & 7.03 & 7.42 \\
\hline 13 & M & $7.8 / 9$ & $7 / 7$ & $96 \%$ & 9 & 18 & Web-Based & 5 & 5.35 & 3.62 \\
\hline 14 & $\mathrm{~N}$ & $5 / 5.5$ & $4 / 4$ & $100 \%$ & 6 & 8 & Mobile App & 7 & 7.05 & 7.35 \\
\hline 15 & $\mathrm{O}$ & $4 / 4.3$ & $5 / 5$ & $100 \%$ & 6 & 10 & Custom Web Service & 6 & 6.27 & 5.73 \\
\hline 16 & $\mathrm{P}$ & $4 / 4.6$ & $5 / 5$ & $100 \%$ & 7 & 10 & Custom Web Service & 5 & 5.3 & 3.29 \\
\hline 17 & Q & $5 / 5.3$ & $7 / 8$ & $91 \%$ & 8 & 15 & Custom Web Service & 6 & 6.23 & 4.74 \\
\hline 18 & $\mathrm{R}$ & $4 / 4.6$ & $4 / 4$ & $100 \%$ & 6 & 8 & Web-Based & 6 & 5.9 & 4.22 \\
\hline 19 & S & $15 / 16.2$ & $6 / 6$ & $100 \%$ & 7 & 12 & Database & 5 & 5.11 & 6.32 \\
\hline 20 & $\mathrm{~T}$ & $42 / 43.5$ & $12 / 12$ & $87 \%$ & 28 & 46 & Security System & 6 & 5.44 & 3.84 \\
\hline
\end{tabular}

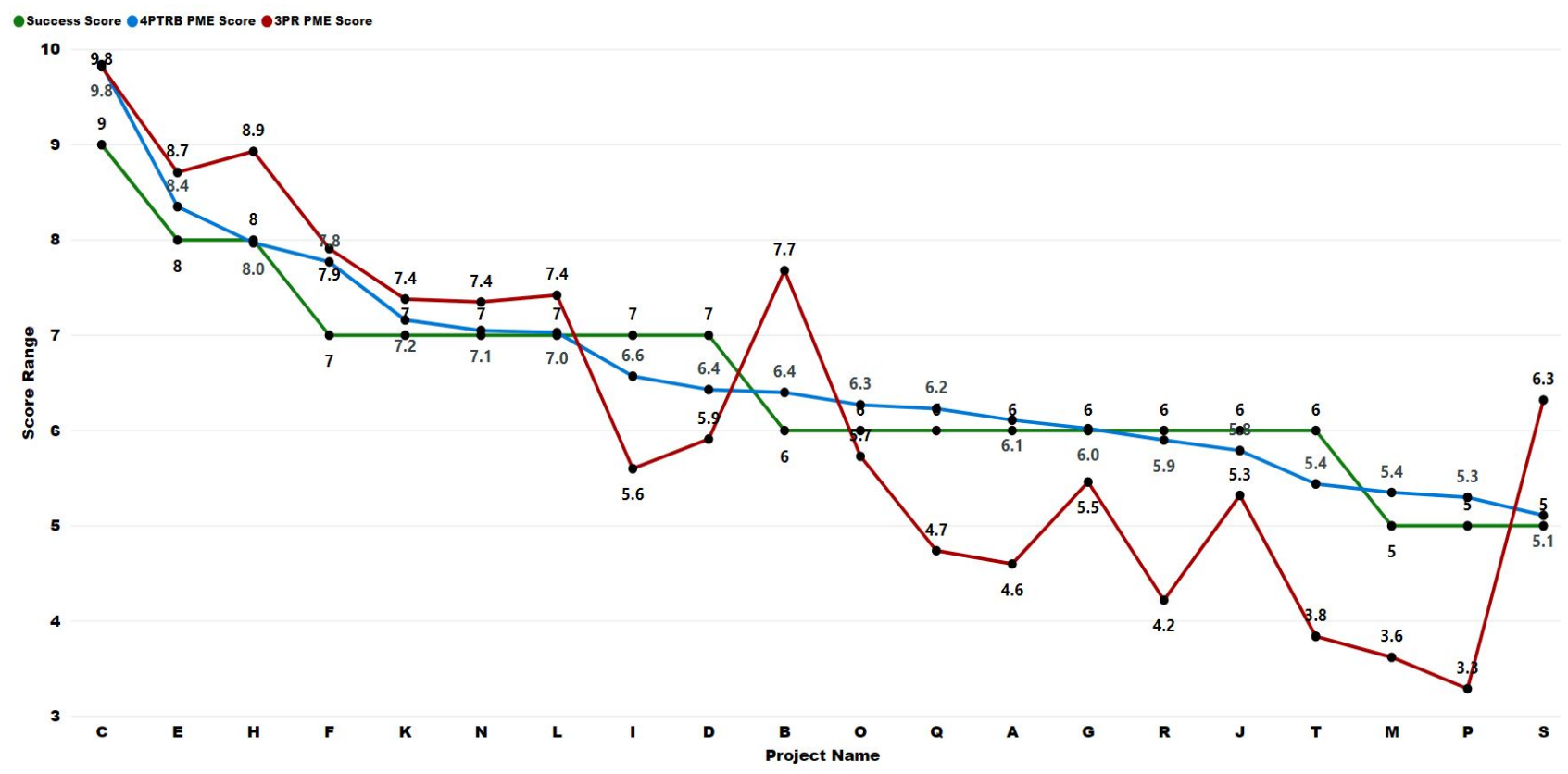

Figure 10. Correlation between the project success score and the 4PTRB PME as well as the 3PR PME scores. 
At the end of each project phase, a measurement of software project management effectiveness can be made as part of the postmortem process to promote iterative best practices. Therefore, recommendations can be drawn up and applied in the corresponding phase of the project for challenging software project management areas. Consequently, the software project manager and top management may perform corrective actions for any project duration. The recommendations of software management areas and sub-areas that need to be considered by the software project manager per phase also have been offered in SPMEV and were not included in the previous works.

\section{Discussion}

The research is focusing on developing a multidimensional framework for software project management effectiveness. The software project management framework derived from existing models and frameworks. However, there is a distinctive characteristic of the 4PTRB framework. Both technology and business management areas are considered in the 4 PTRB framework to cover more aspects and provide a whole inclusive view.

Software projects are also greatly influenced by technology. Managing technology affects the business benefit can be achieved in software projects. Each technology can offer a bundle of privileges besides it has own limitations. Thus choosing the exact technology and aligning it with the business value is a very important consideration for any software project manager.

The survey study has been conducted for validation of the framework also shown that people management has the highest importance in software project management. Previous studies point out that there is a strong positive correlation between software project success and project management effectiveness [37]. Also, the case study results in this paper confirmed the existence of the relationship with empirical evidence. Such findings reinforce the validity of the 4PTRB framework.

\section{Conclusion and Future Work}

To conclude, in this research, a comprehensive software project management framework is introduced based on the frameworks and models used in this stream of research. The framework called 4 PTRB which includes people, process, product, project, technology, risk, and business management areas. Each main area is decomposed into sub-areas of software management. Twenty-eight software management sub-areas shape the framework over the project lifecycle. The 4 PTRB framework offers guidance to the software project manager to less reliance on a specific framework in the direction of increase the chance of delivering a successful software project. The findings of the analysis have been conducted on the data gathered from the survey followed by the case study indicate that the $4 \mathrm{PTRB}$ software project management effectiveness framework proposed in this research is intact, valid and appropriate to be used in software projects. 
As the next steps, the evaluation model of software project management effectiveness besides SPMEV will be introduced in a separate paper. Also, we plan to enhance the 4PTRB framework applicability. Only twenty software projects are included in the case study, so increasing the sample size may reveal new insights. While all the projects in the dataset were developed in Egypt. Future studies should include projects developed in other parts of the world. Moreover, any future work on SPMEV can offer a prediction of the software project's success will be helpful.

\section{Conflicts of Interest}

The authors declare no conflicts of interest regarding the publication of this paper.

\section{References}

[1] Ahmed, A. (2011) Software Project Management: A Process-Driven Approach. 1st Edition. Auerbach Publications, Boca Raton, USA. https://doi.org/10.1145/2464526.2464537

[2] Taherdoost, H. and Keshavarzsaleh, A. (2018) Managing Successful IT Project; Marketing Perspective. Recent Advances on Computational Science and Applications, 144-153.

[3] Dyba, T. (2005) An Empirical Investigation of the Key Factors for Success in Software Process Improvement. IEEE Transactions on Software Engineering, 31, 410-424. https://doi.org/10.1109/TSE.2005.53

[4] Bassam, H.A. (2013) Factors Influencing Project Success Criteria. IEEE 7 th International Conference on Intelligent Data Acquisition and Advanced Computing Systems, Berlin, 12-14 September 2013, 566-571. https://doi.org/10.1109/IDAACS.2013.6662988

[5] Alami, A. (2016) Why Do Information Technology Projects Fail? Procedia Computer Science, 100, 62-71. https://doi.org/10.1016/j.procs.2016.09.124

[6] Jørgensen, M. (2016) A Survey on the Characteristics of Projects with Success in Delivering Client Benefits. Information and Software Technology, 78, 83-94. https://doi.org/10.1016/j.infsof.2016.05.008

[7] Varajão, J. (2016) Success Management as a PM Knowledge Area-Work-in-Progress. Procedia Computer Science, 100, 1095-1102. https://doi.org/10.1016/j.procs.2016.09.256

[8] Ralph, P. and Kelly, P. (2014) The Dimensions of Software Engineering Success. Proceedings of the 36th International Conference on Software Engineering, Hyderabad, May 2014, 24-35. https://doi.org/10.1145/2568225.2568261

[9] Asad, F. and Pinnington, A.H. (2013) Exploring the Value of Project Management: Linking Project Management Performance and Project Success. International Journal of Project Management, 32, 202-217. https://doi.org/10.1016/j.ijproman.2013.05.012

[10] Peters, L. and Moreno, A.M. (2017) Evaluating Software Project Managers: A Multidimensional Perspective. IEEE Software, 34, 104-108. https://doi.org/10.1109/MS.2017.4121223

[11] Ur Rehman, A. and Hussain, R. (2007) Software Project Management Methodologies/Frameworks Dynamics “A Comparative Approach”. International Conference 
on Information and Emerging Technologies, Karachi, 6-7 July 2007, 5. https://doi.org/10.1109/ICIET.2007.4381330

[12] De Amescua, A., García, J., Velasco, M., Martínez, P., Ruiz, B., Llorens, J., et al. (2004) A Software Project Management Framework. Information Systems Management, 21, 78-85. https://doi.org/10.1201/1078/44118.21.2.20040301/80425.11

[13] Dey, P.P., Amin, M., Sinha, B.R., Any, L. and Al Badkoobehi, H. (2018) Current Trends in Software Project Management. Advances in Social Science, Education and Humanities Research, 120, 22-26. https://doi.org/10.2991/mshsd-17.2018.5

[14] Niazi, M., Mishra, A. and Qumer, A. (2018) What Do Software Practitioners Really Think about Software Process Improvement Project Success? An Exploratory Study. Arabian Journal for Science and Engineering, 43, 7719-7735. https://doi.org/10.1007/s13369-018-3140-3

[15] Cerdeiral, C.T. and Santos, G. (2018) Software Project Management in High Maturity: A Systematic Literature Mapping. Journal of Systems and Software, 148, 56-87. https://doi.org/10.1016/j.jss.2018.10.002

[16] Nakigudde, S. (2019) Project Management Models and Software Development Project Success. Master of Science in Information Systems, Makerere University. https://doi.org/10.13140/RG.2.2.36203.08482

[17] Ackah, D. (2019) Project Management Methods, Methodologies, and Frameworks: An Exploration for Study Guild for Project Management Practitioners of Ghana. Project Management Scientific Journal, 1, 61-66. https://doi.org/10.15373/22501991

[18] Kamalakannan, J., Chakrabortty, A., Basak, D. and Babu, L.D.D. (2019) Emerging Trends for Effective Software Project Management Practices. In: Proceedings of the 2nd International Conference on Data Engineering and Communication Technology, Springer, Singapore. https://doi.org/10.1007/978-981-13-1610-4

[19] Ehsan, N., Malik, O.A., Shabbir, F., Mirza, E. and Bhatti, M.W. (2010) Comparative Study for PMBOK \& CMMI Frameworks and Identifying Possibilities for Integrating ITIL for Addressing Needs of IT Service Industry. IEEE International Conference on Management of Innovation \& Technology, Singapore, 2-5 June 2010, 113-116. https://doi.org/10.1109/ICMIT.2010.5492827

[20] Wangenheim, C.G., da Silva, D.A., Buglione, L., Scheidt, R. and Prikladnicki, R. (2010) Best Practice Fusion of CMMI-DEV v1.2 (PP, PMC, SAM) and PMBOK 2008. Information and Software Technology, 52, 749-757. https://doi.org/10.1016/j.infsof.2010.03.008

[21] Futrell, R.T., Shafer, L.I. and Shafer, D.F. (2001) Quality Software Project Management. Prentice Hall, PTR Upper Saddle River, NJ, USA.

[22] Pressman, R.S. and Maxim, B.R. (2014) Software Engineering: A Practitioner's Approach. 8th Edition. McGraw-Hill Inc., New York, NY, USA.

[23] Demir, K.A. (2008) Measurement of Software Project Management Effectiveness. Ph.D. Dissertation in Software Engineering, Naval Postgraduate School, California, USA.

[24] Demir, K.A., Michael, J.B. and Osmundson, J.S. (2009) Approaches for Measuring Software Project Management Effectiveness. International Conference on Software Engineering Research and Practice, Las Vegas, Vol. 2, 613-619. https://doi.org/10.21236/ADA484712

[25] Cullen, C.D. (2011) The Effectiveness of Software Project Management Practices: A Quantitative Measurement. Master's Thesis of Science in Software Engineering, Naval Postgraduate School, California, USA.

[26] Project Management Institute (PMI) (2017) A Guide to the Project Management 
Body of Knowledge (PMBOK). 6th Edition. USA.

[27] Development Team C (2010) CMMI for Development, Version 1.3. Software Engineering Institute (SEI), USA.

[28] Waheed, N. (2014) Cmmi, Prince 2 and Pmbok-The Big Three. International Conference on Advances in Computing and Information Technology, Delhi, 24-25 May 2014, 4, 6-9.

[29] Demir, K.A. (2017) 3PR Framework for Software Project Management: People, Process, Product, and Risk. In: Mahmood, Z., Ed., Software Project Management for Distributed Computing. Springer International Publishing, Cham, 143-170. https://doi.org/10.1007/978-3-319-54325-3_7

[30] Punter, T., Krikhaar, R.L. and Bril, R.J. (2009) Software Engineering Technology Innovation-Turning Research Results into Industrial Success. Journal of Systems and Software, 82, 993-1003. https://doi.org/10.1016/j.jss.2008.12.035

[31] Mikkonen, T., Lassenius, C., Männistö, T., Oivo, M. and Järvinen, J. (2017) Continuous and Collaborative Technology Transfer : Software Engineering Research with Real-Time Industry Impact. Information and Software Technology, 95, 34-45. https://doi.org/10.1016/j.infsof.2017.10.013

[32] Foote, A. and Halawi, L.A. (2016) Knowledge Management Models within Information Technology Projects. Journal of Computer Information Systems, 58, 89-97. https://doi.org/10.1080/08874417.2016.1198941

[33] Ahonen, J.J., Savolainen, P., Merikoski, H. and Nevalainen, J. (2015) Reported Project Management Effort, Project Size, and Contract Type. Journal of Systems and Software, 109, 205-213. https://doi.org/10.1016/j.jss.2015.08.008

[34] Jørgensen, M., Mohagheghi, P. and Grimstad, S. (2017) Direct and Indirect Connections between Type of Contract and Software Project Outcome. International Journal of Project Management, 35, 1573-1586. https://doi.org/10.1016/j.ijproman.2017.09.003.

[35] Gomes, J. and Romão, M. (2016) Improving Project Success: A Case Study Using Benefits and Project Management. Procedia Computer Science, 100, 489-497. https://doi.org/10.1016/j.procs.2016.09.187

[36] Barghoth, M.E. (2019) Survey Results. https://forms.office.com/Pages/AnalysisPage.aspx?id=OS8P8PEvH0OrqTJz-K0ZDh YKm6x4A7tLjsDLHKcQ7DdURVZOSIRKOU43UFINSDQwTk5UMFpBQ1dBOC4 u\&AnalyzerToken=FNKKY71WFi5pRLTFG5jst1MPFF53IgvW

[37] Umebayashi, T., Committee, R., Chairperson, C., Faculty, H.S., Member, C., Faculty, H.S., et al. (2011) The Correlation between Project Management Effectiveness and Project Success. Ph.D. Dissertation, College of Management and Technology, Walden University, Minneapolis. https://doi.org/UMI:3257958 